\title{
Point-of-Care Gastric Ultrasound in a Pediatric Patient After Bowel Preparation: A Case Report
}

This article was published in the following Dove Press journal:

Clinical and Experimental Gastroenterology

\author{
Yoshikazu Yamaguchi (iD ${ }^{1,2}$ \\ Steven P Zadora' \\ Colleen Flahive ${ }^{3}$ \\ John M Russo ${ }^{3}$ \\ Gregory S Maves ${ }^{1,2}$ \\ Alok Moharir ${ }^{1,2}$ \\ Joseph D Tobias $\mathbb{D}^{1,2}$ \\ 'Department of Anesthesiology and Pain \\ Medicine, Nationwide Children's \\ Hospital, Columbus, Ohio, USA; \\ ${ }^{2}$ Department of Anesthesiology and Pain \\ Medicine, The Ohio State University, \\ Columbus, Ohio, USA; ${ }^{3}$ Department of \\ Pediatrics and the Division of Pediatric \\ Gastroenterology, Nationwide Children's \\ Hospital \& the Ohio State University, \\ Columbus, Ohio, USA
}

Correspondence: Yoshikazu Yamaguchi Department of Anesthesiology and Pain Medicine, Nationwide Children's Hospital, 700 Children's Drive, Columbus, Ohio 43205, USA

Tel +I 614 722-4200

Fax +I 614 722-4203

Email yoshikaz@rd6.so-net.ne.jp

\begin{abstract}
Polyethylene glycol electrolyte solutions (PEG, NuLYTELY ${ }^{\circledR}$ ) are widely used to prepare the GI tract before colonoscopy or barium enema examinations. Although PEG appears as a clear liquid, the optimal interval for sedation or general anesthesia after the last administration of these solutions is unclear and controversial in the anesthetic literature. We present a 3-year-old patient with intermittent bloody stools who required anesthetic care for esophagogastroduodenoscopy (EGD) and colonoscopy. Given the controversial nil per os time with the use of PEG-containing solutions, point-of-care gastric ultrasound was performed to evaluate gastric contents and gastric volume before the induction of anesthesia.
\end{abstract}

Keywords: bowel preparation, point-of-care ultrasound, colonoscopy

\section{Introduction}

Anesthesia-related pulmonary aspiration is a rare, but potentially serious complication with an estimated incidence of 5.5 in 10,000 cases. ${ }^{1}$ In the study of Eisler et al, the aspiration event resulted in prolonged intubation (12\%), hypoxemia (30\%), or pneumonia (3\%). ${ }^{1}$ American Society of Anesthesiologists' (ASA) guidelines state that clear liquids may be ingested for up to 2 hours before a procedure requiring general anesthesia, regional anesthesia, or procedural sedation. ${ }^{2}$ Polyethylene glycol electrolyte solutions (PEG, NuLYTELY ${ }^{\circledR}$ ) are widely used to cleanse the bowel prior to colonoscopy or barium examinations. Although PEG appears as a translucent clear liquid, more than $90 \%$ of anesthesiologists do not regard PEG as clear liquid given the presence of PEG and the risk of significant pulmonary complications related to aspiration, which may result in death. ${ }^{3,4}$ Moreover, opinions regarding the optimal fasting time between the provision of sedation or general anesthesia and the last ingestion of PEG varies between anesthesiologists and gastroenterologists. $^{3}$

Given its non-invasive nature and ease of applicability, point-of-care gastric ultrasound has become more common not only in the adult population, but also in the pediatric population to evaluate gastric volume and contents. ${ }^{5,6}$ The gastric volume is calculated by the ultrasound measurement of the cross-sectional area (CSA) of the gastric antrum. The density of the fluid in the stomach can also be evaluated as either clear fluid or containing solid material. Preliminary studies have suggested its efficacy in evaluating the patient's nil per os (NPO) status and the potential for aspiration. An empty stomach (grade 0 ) and clear fluid $(<1.2-1.5 \mathrm{~mL} / \mathrm{kg}$ ) (grade 1) are regarded as low risk for aspiration. Clear fluid $\left(\geq 1.2-1.5 \mathrm{~mL} / \mathrm{kg}\right.$ ) or solid contents are regarded as high risk for aspiration. ${ }^{6,7}$

We present a 3-year-old child who presented for urgent esophagogastroduodenoscopy (EGD) and colonoscopy. The patient had received PEG for bowel preparation that was 
discontinued only 3 hours prior to the anesthetic care. Gastric contents and volumes were evaluated using gastric ultrasound in the pre-operative unit. Written Health Insurance Portability and Accountability Act (HIPAA) authorization was obtained from a parent for preparation, presentation, and publication of this case report. Presentation follows the guidelines of the Institutional Review Board of Nationwide Children's Hospital.

\section{Case Description}

The patient was a 3-year-old, 16.5 kilogram girl with intermittent bloody stool who presented for esophagogastroduodenoscopy and colonoscopy. Her past medical history was significant for myelodysplastic syndrome, history of bone marrow transplantation, and hypertension. Her medication regimen included omeprazole $10 \mathrm{mg}$ once a day, enalapril $2 \mathrm{mg}$ once a day, and isradipine $1.5 \mathrm{mg}$ once a day. PEG solution $\left(\right.$ NuLYTELY $\left.^{\circledR}\right)$ was administered via nasogastric tube at $50 \mathrm{~mL} / \mathrm{hr}$ starting 40 hours prior to the procedure and increased $50 \mathrm{~mL} / \mathrm{hr}$ every 2 hours to a maximum of $200 \mathrm{~mL} /$ hr. PEG was discontinued 3 hours prior to the procedure. Point-of-care gastric ultrasound was performed in the preoperative care unit using a SonoSite X-porte (FUJIFILM SonoSite inc, Bothwell, WA) with a mid-frequency (3-8 $\mathrm{MHz}$ ) curvilinear probe with standard abdominal settings. Target pattern was confirmed in the supine position, which demonstrated an empty stomach (Figure 1). Only a small amount of the liquid was observed in right lateral decubitus position (RLD) and the cross-sectional area of the gastric antrum was $2.65 \mathrm{~cm}^{2}$, which is equal to $0.24-0.42 \mathrm{~mL} / \mathrm{kg}$ (Figure 2). Her aspiration risk classification was grade 1, which is empty stomach in the supine position and clear fluid visible in the RLD. ${ }^{8}$ In the operating room, standard American Society of Anesthesiologists' monitors were placed. Following pre-oxygenation with $100 \%$ oxygen, anesthesia was induced with propofol $(100 \mathrm{mg})$ and lidocaine (20 mg). Bag-valve-mask ventilation was performed without difficulty followed by the administration of rocuronium (20 mg). Direct laryngoscopy was performed with a Macintosh 2 blade and revealed a Cormack-Lehane Grade 1 view. A $4.5 \mathrm{~mm}$ cuffed tracheal tube was placed on the first attempt. Anesthesia was maintained by a continuous propofol infusion. EGD revealed that the stomach was empty with limited aspiration of any residual fluid (Figure 3). After completion of the procedure, the propofol infusion was discontinued. Ondansetron (2.4 mg), dexmedetomidine (12 $\mu \mathrm{g})$, and sugammadex (60 mg) were administered prior to tracheal extubation. The patient was transported to the postanesthetic care unit and then to the general inpatient ward. Her postoperative course was uncomplicated without hypoxemia or the need for oxygen administration.

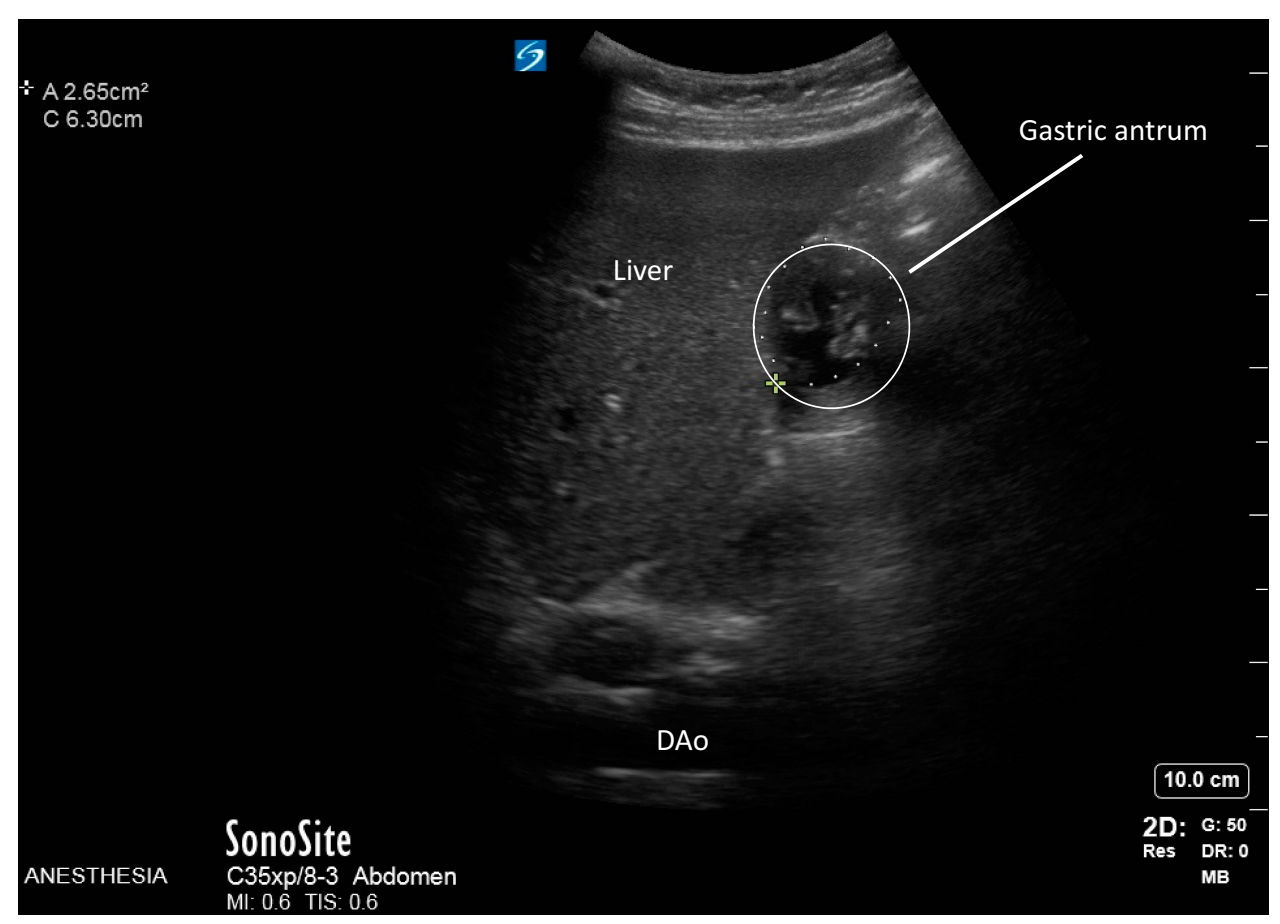

Figure I Preoperative point-of-care gastric ultrasound in the supine position 3 hours after discontinuation of the polyethylene glycol solution. The gastric antrum is observed next to the left lobe of the liver with a target sign, which suggests an empty stomach. DAo, descending aorta. 


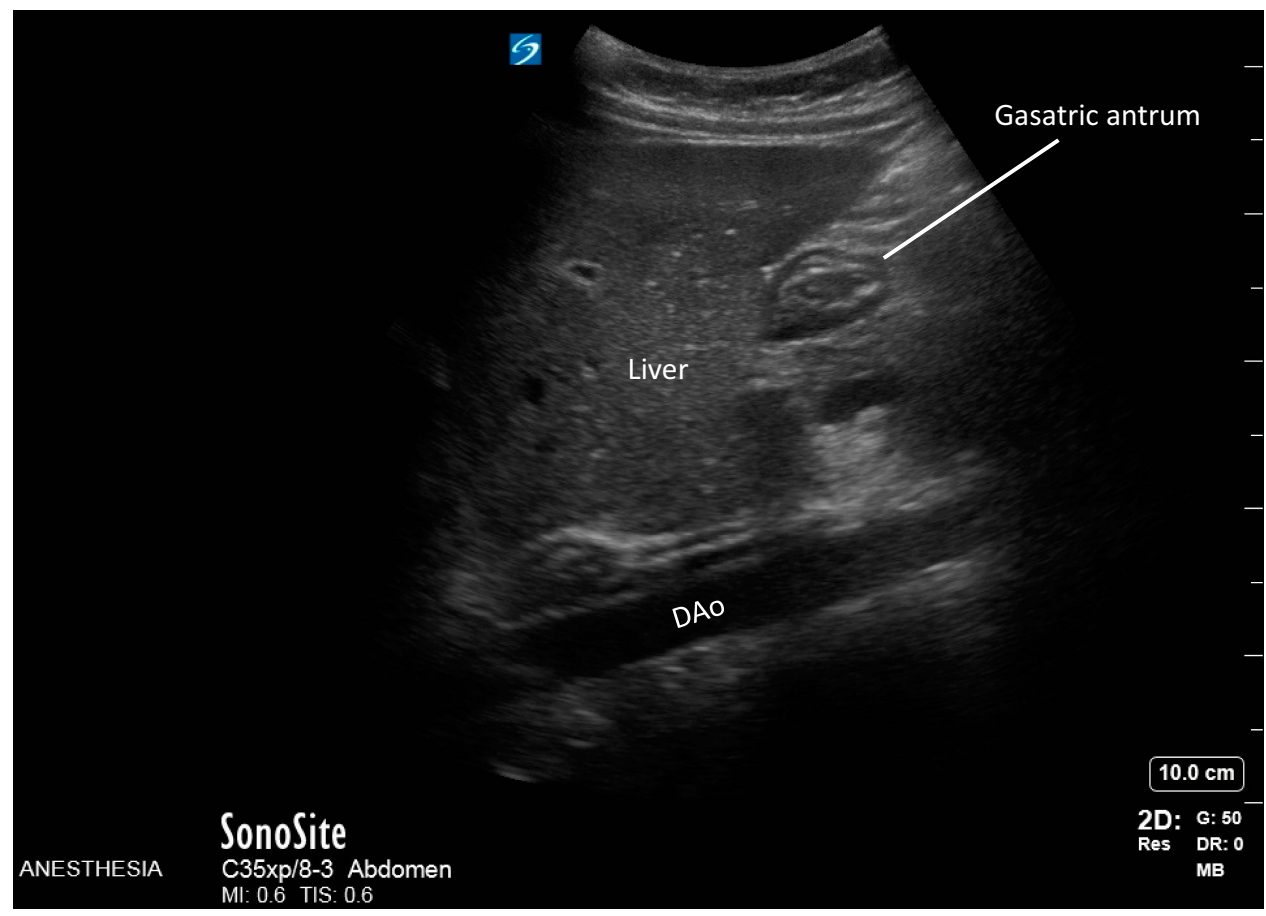

Figure 2 Point-of-care gastric ultrasound in right lateral decubitus position. There is a small amount of clear liquid in the stomach. The cross-sectional area of the gastric antrum was $2.65 \mathrm{~cm}^{2}$.

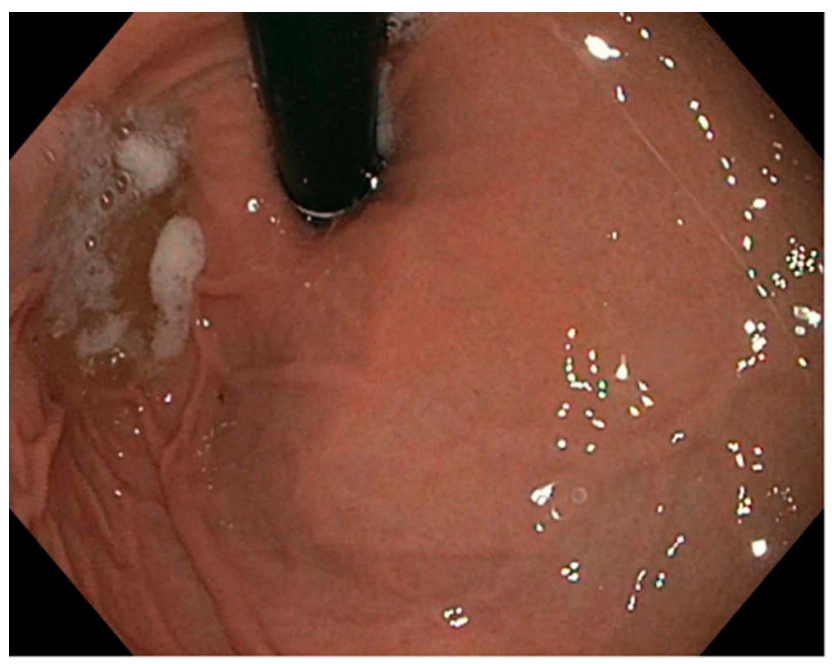

Figure 3 Image obtained during esophagogastroduodenoscopy. There was minimal residual gastric fluid which could not be aspirated into the suction canister.

\section{Discussion}

Given its efficacy and tolerability, PEG is a popular solution for bowel cleansing prior to colonoscopy. Although PEG appears as a clear liquid, it is hyperosmotic when compared to other clear liquids. The optimal time interval between the administration of these solutions and the start of sedation or anesthetic care is controversial. The majority (96\%) of anesthesiologists recommended waiting longer than 2 hours until sedation, in contrast to $26 \%$ of gastroenterologists. ${ }^{3}$ Recommendations for general anesthesia vary with NPO times of 4-6 hours.

When perioperative aspiration occurs, the severity of pulmonary damage relates to the volume of fluid as well as its characteristic (particulate, $\mathrm{pH}$ ). Moreover, severe pneumonia after PEG aspiration has been reported. ${ }^{4}$ Therefore, the optimal NPO time for PEG remains unclear. Agrawal et al evaluated 150 adult patients scheduled for colonoscopy and reported that the mean gastric residual volume (GRV) after PEG and fasting 2-3 hours was $21 \pm 24 \mathrm{~mL}$, assessed using ultrasound. Although the authors concluded that sedation can be performed safely 2 hours after bowel preparation, the GRV was more than $100 \mathrm{~mL}$ (high risk of aspiration) in 4 of 150 patients in the study cohort. 9

Point-of-care ultrasonography (POCUS) is defined as ultrasonography performed in real time at the patient's bedside. POCUS has now become state-of-the-art for various medical fields including surgeons, anesthesiologists, and emergency room physicians. ${ }^{9}$ Point-of-care gastric ultrasound is being used more frequently during the perioperative period to evaluate gastric volume and contents. ${ }^{10,11}$ The crosssectional area of antrum in the right-lateral decubitus (RLD) position is used to evaluate the gastric residual volume (GRV). The gastric antrum is identified in a sagittal plane between the left lobe of the liver and the pancreas at the level of the 
descending aorta and superior mesenteric artery or inferior

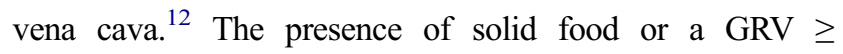
$1.2-1.5 \mathrm{~mL} / \mathrm{kg}$ is regarded as a high risk for pulmonary aspiration. As noted in our case, an empty stomach in the supine is regarded as low risk despite the administration of NuLYTELY $^{\circledR}$ up to 3 hours prior to the procedure. ${ }^{7,8}$

The optimal NPO duration is affected not only by the types of food or liquid, but also by patient-related factors. Abdominal symptoms and comorbid conditions such as gastroesophageal reflex, diabetes, and opioid administration may result in gastroparesis and increased GRV. In summary, when there is a potential concern for aspiration or controversy related to the type of fluid and necessary NPO times, POCUS may be helpful in guiding anesthetic care.

\section{Abbreviations}

POCUS, point-of-care ultrasound; ASA, American Society of Anesthesiologists; PEG, polyethylene glycol electrolyte solution; EGD, esophagogastroduodenoscopy; HIPAA, Health Insurance Portability and Accountability Act; RLD, right lateral decubitus position; GRV, gastric residual volume.

\section{Disclosure}

The authors report no conflicts of interest in this work.

\section{References}

1. Eisler L, Huang G, Lee K-EM, et al. Identification of perioperative pulmonary aspiration in children using quality assurance and hospital administrative billing data. Ped Anesthesia. 2018;28(3):218-225. doi:10.1111/pan.13319
2. Practice Guidelines for Preoperative Fasting and the Use of Pharmacologic Agents to Reduce the Risk of Pulmonary Aspiration: Application to Healthy Patients Undergoing Elective Procedures: An Updated Report by the American Society of Anesthesiologists Task Force on Preoperative Fasting and the Use of Pharmacologic Agents to Reduce the Risk of Pulmonary Aspiration. Anesthesiology. 2017;126(3):376-393.

3. Agrawal D, Marull J, Tian C, Rockey DC. Contrasting perspectives of anesthesiologists and gastroenterologists on the optimal time interval between bowel preparation and endoscopic sedation. Gastroenterol Res Pract. 2015;2015:497176. doi:10.1155/2015/497176

4. de Graaf P, Slagt C, de Graaf JL, Loffeld RJ. Fatal aspiration of polyethylene glycol solution. Neth J Med. 2006;64(6):196-198.

5. Kruisselbrink R, Gharapetian A, Chaparro LE, et al. Diagnostic accuracy of point-of-care gastric ultrasound. Anesth Analg. 2019;128(1):89-95. doi:10.1213/ANE.0000000000003372

6. Spencer AO, Walker AM, Yeung AK, et al. Ultrasound assessment of gastric volume in the fasted pediatric patient undergoing upper gastrointestinal endoscopy: development of a predictive model using endoscopically suctioned volumes. Paediatr Anaesth. 2015;25 (3):301-308. doi:10.1111/pan.12581

7. Van de Putte P, Perlas A. Ultrasound assessment of gastric content and volume. Br J Anaesth. 2014;113(1):12-22. doi:10.1093/bja/aeu151

8. Perlas A, Van De Putte P, Van Houwe P, Chan VWS. I-AIM framework for point-of-care gastric ultrasound. Br J Anaesth. 2016;116 (1):7-11. doi:10.1093/bja/aev113

9. Agrawal D, Elsbernd B, Singal AG, Rockey D. Gastric residual volume after split-dose compared with evening-before polyethylene glycol bowel preparation. Gastrointest Endosc. 2016;83:574-580.

10. Alakkad H, Kruisselbrink R, Chin KJ, et al. Point-of-care ultrasound defines gastric content and changes the anesthetic management of elective surgical patients who have not followed fasting instructions: a prospective case series. Can J Anesthesia/J canadien d'anesthésie. 2015;62(11):1188-1195. doi:10.1007/s12630-015-0449-1

11. Tampo A, Suzuki A, Ijiri E, Kunisawa T, Iwasaki H. Preanesthetic gastric assessment with sonography for a patient with a full stomach. J Clin Anesth. 2013;25(2):164-165. doi:10.1016/j.jclinane.2012.10.004

12. Van de Putte P, Vernieuwe L, Jerjir A, Verschueren L, Tacken M, Perlas A. When fasted is not empty: a retrospective cohort study of gastric content in fasted surgical patientsdagger. $\mathrm{Br} J$ Anaesth. 2017;118(3):363-371.
Clinical and Experimental Gastroenterology

\section{Publish your work in this journal}

Clinical and Experimental Gastroenterology is an international, peerreviewed, open access, online journal publishing original research, reports, editorials, reviews and commentaries on all aspects of gastroenterology in the clinic and laboratory. This journal is indexed on American Chemical Society's Chemical Abstracts Service (CAS).

\section{Dovepress}

The manuscript management system is completely online and includes a very quick and fair peer-review system, which is all easy to use. Visit http://www.dovepress.com/testimonials.php to read real quotes from published authors. 